American Journal of Applied Sciences 4 (11): 946-949, 2007

ISSN 1546-9239

(C) 2007 Science Publications

\title{
Side Effects and Complications of Dental Materials on Oral Cavity
}

\author{
${ }^{1}$ Zahra Atai and ${ }^{2}$ Mohammad Atai \\ ${ }^{1}$ Faculty of Dentistry, Kerman University of Medical Sciences, Kerman, Iran \\ ${ }^{2}$ Department of Polymer Science, Iran Polymer and Petrochemical Institute (IPPI), Tehran, Iran
}

\begin{abstract}
Development of dental materials has had a great impact on the modern dentistry. The materials ranging from polymers to metals have different applications in dentistry. Besides their important role in healing or improving the function of oral tissues, the materials may show side effects which may, in some cases, lead to severe lesions. In this review the side effects have been summarized considering a new classification for dental materials according to the duration of their applications as temporary or permanent materials. The side effects of the materials are then discussed based on clinical and cellular views.
\end{abstract}

Key words: Dental materials, side effects, oral tissues, cytotoxicity, lesions

\section{INTRODUCTION}

Dental materials have been categorized in different ways. In this review a new criterion has been considered to categorize them into different classes. Dental materials are divided upon the time period of their application as temporary and permanent materials. The temporary materials are applied for a short period of time usually to heal a tissue or improve its function. Although the materials have often temporary effects, the effects may recur every time which they are applied. The permanent materials are often used to replace a tissue or recover its function and should keep the function as long as possible (Table 1).

Table 1: Classification of dental materials

\begin{tabular}{ll}
$\begin{array}{l}A- \\
\text { Permanent }\end{array}$ & $\begin{array}{l}\text { composites, etc. } \\
\text { materials }\end{array}$ \\
& - Reconstructive materials: Denture \\
& base, Implants, etc. \\
& - Therapeutic materials: \\
$B-$ & -Medicine, Mouth washes, tooth \\
Temporary & pastes, chewing gum, food additives \\
materials & - Devices: Brackets, orthodontic \\
& plaque, wires,.. \\
\hline
\end{tabular}

The side effects of the materials are then discussed according to this classification considering clinical and cellular views.

Numerous studies have been performed to understand and improve physical and mechanical properties of dental materials ${ }^{[1-10]}$. Fewer attempts have been made to assess the biocompatibility of the materials. Although physical and mechanical properties are very important in selecting a material for dental application, the biological characteristics of the material cannot be isolated from its physical and mechanical properties and biological considerations should also be associated with the selection and use of materials designed for the oral cavity.

When a biomaterial is placed in contact with the tissues and fluids of the human body, there are invariably some forms of interaction between the material and the biological environment. This interaction forms the subject of biocompatibility ${ }^{[11]}$. A material may be said to be biocompatible when it has the quality of being non-destructive in the biological environment. It is important to appreciate that this interaction works both ways. That is, the material may be affected in some way by the biological environment, and equally, the biological environment may be affected by the material ${ }^{[12]}$. The biological reactions can take place either at a local level or far removed from the site of contact (i.e. systemically). The latter is a very important consideration. Because it may not always be readily apparent that clinical symptoms such as dermatological, rheumatic or neural reactions could be associated with a biomaterial. Both patients and the dental personnel are exposed to these interactions and the potential risks, with the patient being the recipient of the restorative materials and the dental personnel handing many of the materials on a daily basis ${ }^{[12]}$.

Material that is to be used in the oral cavity should be harmless to the pulp and the soft tissues. Also, it

Corresponding Author:

Zahra Atai, DDS, MSD, Assistant professor in oral medicine, Faculty of dentistry, Kerman University of Medical Sciences, Kerman, Iran 
should contain no toxic diffusible substance that can be absorbed into the circulatory system to cause a systemic toxic response. The material should be free of potential sensitizing agent that could lead to an allergic response. Finally, the material should have no carcinogenic potential. In the sections that follow, where indicated, reference will be made to reported allergic, sensitizing, or toxic effects of components found in certain restorative materials, such as mercury in dental amalgam or nickel in casting alloys ${ }^{[13]}$.

This study evaluates almost all side effects and orders them based on :i-clinical view, $i i$-region, and iiitype of materials.

\section{Side effects on oral mucosa (based on clinical view): Lichenoid reaction}

Lichenoid reactions and lichen planus exhibit similar histopathologic features. Lichenoid reactions are differentiated form lichen planus on the basis of their association with the administration of a drug, contact with a metal, the use of a food flavoring, or systemic disease and their resolution when the drug or other factor is eliminated or when the disease is treated ${ }^{[14,15]}$. Clinically, lichenoid lesions may exhibit the classic appearance of lichen planus, but atypical presentations are seen. Some of the dermatologic lesions included in this category show little clinical lichenification ${ }^{[14]}$.

Amalgam tattoo: By far, the most common source of solitary or focal pigmentation in the oral mucosa is the amalgam tattoo. The lesions are macular and bluish gray or even black and are usually seen in the buccal mucosa, gingivae, or palate. Importantly, they are found in the vicinity of teeth with large amalgam restorations or crowned teeth that probably had amalgams removed when the teeth were being prepared for the fabrication of the crown. Such lesions are the consequence of an iatrogenic mishap whereby the dentist's bur, loaded with small amalgam particles that accumulate during the removal of amalgam, accidentally veers into the adjacent mucosa and traumatically introduces the metal flecks ${ }^{[14,15]}$.

Contact stomatitis: Contact allergy results from a delayed hypersensitivity reaction that occurs when antigens of low molecular weight penetrate the skin or mucosa of susceptible individuals. These antigens combine with epithelial-derived proteins to form haptens that bind to Langerhan's cells migrate to the regional lymph nodes and present the antigen to $\mathrm{T}$ lymphocytes, which become sensitized and undergo clonal expansion. After re-exposure to the antigen, sensitized individual develop an inflammatory reaction confined to the site of contact. Since the reaction resulting from contact allergy appears as nonspecific inflammation, contact dermatitis is unknown, but it is believed to be significantly less common than contact dermatitis for the following reasons:

a. Saliva quickly dilutes potential antigens and physically washes them away and digests them before they can penetrate the oral mucosa.

b. Since the oral mucosa is more vascular than the skin, potential antigens that do penetrate the mucosa are rapidly removed before an allergic reaction can be established.

c. The oral mucosa has less keratin than does the skin, decreasing the possibility that haptens will be formed $^{[14]}$.

Contact stomatitis may result from contact with dental materials, oral hygiene products, or foods. Common causes of contact oral reactions are cinnamon or peppermint which are frequently used as flavoring agents in food, candy, and chewing gum, as well as oral hygiene products such as toothpaste, mouthwash and dental floss ${ }^{[14,15]}$.

Dental materials that have been reported to cause cases of contact allergic stomatitis include mercury in amalgam, gold in crowns, free monomer in acrylic, and nickel on orthodontic wire. Pyrophosphates and zinc citrate, which are components of tartar control toothpaste, cause superficial peeling of the mucosa in some users, but this reaction is believed to be caused by physical irritation rather than an allergic reaction ${ }^{[14,15]}$.

Geographic lesions: Geographic tongue (erythema migrans, benign migratory glossitis, erythema areata migrans, stomatitis areata migrans) is a common benign condition affecting primarily the dorsal surface of the tongue. Its incidence varies from slightly over $2 \%$ in the US population to 11 to $16 \%$ in other populations. The conditions are usually asymptomatic, but in one study of patients who experienced burning in the mouth, the burning was associated with geographic tongue in $24 \%$ of the patients. Metal material as amalgam, gold, orthodontic wires can lead to geographic tongue ${ }^{[14,15]}$.

Recurrent aphthous stomatitis(RAS): RAS is a disorder characterized by recurring ulcers confined to the oral mucosa in patients with no other signs of disease. The current concept is that RAS is a clinical syndrome with several possible causes. The major factors identified include heredity, hematologic deficiencies, and immunologic abnormalities. The best documented factor is heredity ${ }^{[14]}$.

A detergent present in toothpaste, sodium lauryl sulfate (SLS), was suspected as an etiologic factor in RAS development, but a recent double-blind crossover 
study showed that use of an SLS-free toothpaste had no significant effect on ulcer development ${ }^{[14,15]}$.

\section{Side effects on teeth (based on clinical and cellular view): Staining}

Dental restorative materials, especially amalgam, can result in black-gray discolorations of teeth. This most frequently arises in younger patients who have more open dentinal tubules. Large class II proximal restorations of posterior teeth can produce discoloration of the overlying facial surface. In addition, deep lingual metallic restorations on anterior incisors can significantly stain underlying dentin and produce visible grayish discoloration on the labial surface. To help reduce discoloration, the clinician should not restore endodontically treated anterior teeth with $\operatorname{amalgam}^{[16,17]}$.

Tooth's pulp reactions: Few, if any, dental materials are totally inert from a physiological standpoint. They contain a variety of potentially toxic or irritating ingredients. In addition, the chemical reactions that occur during the setting or hardening of the material may produce an undesirable effect upon the pulp.

Thus it is apparent that the dental pulp may be subjected to various types of injury before, during, and after restoration of the carious tooth ${ }^{[12]}$.

To summarize, heat and desiccation during cavity preparation can cause injury to the pulp. Damage may occur during the insertion of the restorative material, as by the pressure of condensing direct gold or amalgam and the hydraulic pressure produced during the segmentation of a crown. Components of restoratives and chemicals generated during setting can be harmful. After placement, thermal shock and galvanism can cause hypersensitivity. Bacteria penetrating along the tooth-restoration, interface may contribute to pulpal irritation, as well as secondary caries ${ }^{[12]}$.

Recognizing the importance of the biological characteristics of dental materials, the American Dental Association has developed a series of tests that should provide acceptable methodology for screening materials for their toxicity and irrational characteristics. With the advent of such a specification, the dentist is assured of a specific biological index for every material used in the oral cavity, in addition to its certification as to suitability from a mechanical standpoint. ${ }^{[12]}$

Side effects on oral mucosa and teeth (based on the type of materials): There are many materials that are used in dentistry, so they may show numerous side effects, therefore the side effects of some commonly used dental materials are summarized in the Table 2.
Table 2: Side effects on oral mucosa and teeth (based on the type of materials)

\begin{tabular}{|c|c|}
\hline Materials & Effects \\
\hline $\begin{array}{c}\text { Mouth washes, } \\
\text { tooth pastes, } \\
\text { impression materials } \\
\text { (temporary materials) }\end{array}$ & $\begin{array}{l}\text { Hypersensitivity reactions } \\
{[17,18,19,20,21]}\end{array}$ \\
\hline Amalgam & $\begin{array}{l}\text { Discoloration of mucosa, } \\
\text { gingiva, teeth }{ }^{[22,23,24]}\end{array}$ \\
\hline $\mathrm{Ni}-\mathrm{Cr}$ alloy & Discoloration of gingival $^{[24]}$ \\
\hline $\begin{array}{l}\text { Mercury ( in } \\
\text { amalgam) }\end{array}$ & $\begin{array}{l}\text { Hypersensitivity reactions in } \\
\text { gingiva, buccal mucosa, tongue, } \\
\text { skin of the back of the hands } \\
\text { lichenoid reaction }[25,26,27,28,29,30]\end{array}$ \\
\hline MTA with $\mathrm{CHX}$ & $\begin{array}{l}\text { Decrease the percentage of } \\
\text { fibroblasts and macrophages in } S \\
\text { phase (DNA) synthesis, Increase } \\
\text { their cytotoxicity }{ }^{[31]}\end{array}$ \\
\hline Bis-GMA & $\begin{array}{l}\text { Induced a significant high } \\
\text { embryotoxic/teratogenic effect } \\
\text { over a large range of } \\
\text { concentration }{ }^{[31,32]}\end{array}$ \\
\hline TEGDMA & $\begin{array}{l}\text { Evidence of a possible risk } \\
\text { factor for tumor initiation in } \\
\text { human salivary glands (over a } \\
\text { large range of concentration) }\end{array}$ \\
\hline Ag-Sn alloy & Discoloration of mucosa ${ }^{[34]}$ \\
\hline $\begin{array}{l}\text { Oral hygiene } \\
\text { products, food } \\
\text { additives }\end{array}$ & $\begin{array}{l}\text { Contact allergy in the } \\
\text { mouth }^{[35]}\end{array}$ \\
\hline $\mathrm{CHX}$ & $\begin{array}{l}\text { Tooth discoloration, taste } \\
\text { disorder }{ }^{[24]}\end{array}$ \\
\hline Stannous fluoride & Tooth discoloration \\
\hline $\begin{array}{l}\text { Uncured primers } \\
\text { and adhesives of } \\
\text { dentin bonding resins }\end{array}$ & $\begin{array}{c}\text { Cytotoxic to L } 929 \text { Cells } \\
\text { (Monomers) clinical exposure to } \\
\text { this materials should be } \\
\text { minimized }^{[36]}\end{array}$ \\
\hline $\begin{array}{l}\text { Denture relining } \\
\text { materials }\end{array}$ & May be cytotoxic and irritant \\
\hline
\end{tabular}

\section{CONCLUSION}

Dental materials, which have now found widespread applications in dentistry, in spite of their good physical and mechanical properties and excellent esthetic characteristics, may, in turn, cause some side effects. The side effects may lead to severe lesions in oral cavity or far from the application place of the materials. Dental materials may be categorized in two temporary or permanent materials and the related side effects can be studied based on clinical view, region, and the type of materials. 


\section{REFERENCES}

1. Turssi, C.P., B.M. Purquerio and M.C. Serra, 2003. Wear of dental resin composites: Insights into underlying processes and assessment methods-a review. J. Biomed. Mater. Res. Part B: Appl. Biomater.: 65B: 280-285.

2. Ruddell, D.E., M.M. Maloney and J.Y. Thompson, 2002. Effect of novel filler particles on the mechanical and wear properties of dental composites. Dent. Mater., 18: 72-80.

3. Atai, M., M. Nekoomanesh, S.A. Hashemi and S. Amani, 2004. Physical and mechanical properties of an experimental dental composite based on a new monomer. Dent. Mater., 20: 663-668.

4. Turssi, C.P., J.L. Ferracane and K. Vogel, 2005. Filler features and their effects on wear and degree of conversion of particulate dental resin composites. Biomaterials, 26: 4932-4937.

5. Zandinejad, A.A., M. Atai and A. Pahlevan, 2006. The effect of ceramic and porous fillers on the mechanical properties of experimental dental composites. Dent. Mater., 22: 382-387.

6. Atai M., D.C. Watts and Z. Atai, 2005. Shrinkage strainrates of dental resin-monomer and composite systems. Biomaterials, 26: 5015-5020.

7. Atai M. and D.C. Watts, 2006. A new kinetic model for the photopolymerization shrinkage-strain of dental composites and resin-monomers. Dent. Mater., 22: 785791.

8. Atai M., M. Ahmadi, S. Babanzadeh and D.C. Watts, 2007. Synthesis, characterization, shrinkage and curing kinetics of a new low-shrinkage urethane dimethacrylate monomer for dental applications. Dent. Mater. , 23: 1030-1041.

9. Atai M., E. Yassini, M. Amini and D.C. Watts, 2007. The effect of a leucite-containing ceramic filler on the abrasive wear of dental composites. Dent. Mater., (in press).

10. Heydecke G., F. Butz, J.R. Binder and J.R. Strub, 2007. Material characteristics of a novel shrinkage-free $\mathrm{ZrSiO}_{4}$ ceramic for the fabrication of posterior crowns. Dent. Mater., 23: 785-791.

11. Roberson T.M., H. Heyman, J. Edward and J.R. Swift, 2002. Sturdevant's Art and Science of Operative Dentistry, 4th ed., St. Louis, Mosby, pp: 16-36.

12. Van Noort R., 1994. Introduction to Dental Materials, 1 st ed., London, Mosby, pp: 2-4.

13. Phillips R.W., 1991. Skinner's Science of Dental Materials, 9th ed., Philadelphia, Saunders Co., pp: 61-67.

14. Greenberg M.S. and M. Glick, 2003. Burket's Oral Medicine, Diagnosis and Treatment. 10th ed., Hamilton, Decker Inc., pp: 60,61,114,115.

15. Little J.W., D.A. Falace, C.S. Miller and N.L. Rhodus, 2002. Dental Management of Medically Compromised Patients. 6 th ed., St. Louis, Mosby, pp: 314-330.

16. Neville B.W., D.D. Damm, C.M. Allen and J.E. Bouquot, 2002. Oral \& Maxillofacial Pathology, 2th ed., Philadelphia, Saunders Co., pp: 63-64.

17. Shafer W.G., M.K. Hine, B.M. Levy and C.E. Tomich, 1983. A textbook of Oral Pathology. 4th ed., Philadelphia, Saunders Co., pp: 528-594.

18. Abdolahi M. and M. Radfar, 2003. A Review of Drug Induced Oral Reactions. J. contemp. Dent. Pract. 4: 10-31.

19. Axell T., 2001. Hypersensitivity of Oral Mucosa: Clinics and Pathology. Acta. Odontal. scand., 59: 315-319.

20. http://www.Health.gov/environment/amalgam1/appendix I- section III htm. Accessible on 31/01/2006.
21. Leber A.P., 2001. Human exposures to monomer resulting from consumer contact with polymers. Chemico-Biological Interactions. 135-136. 215-220

22. Buchner A., 2004. Amalgam tattoo (amalgam pigmentation) of the mucosa: clinical manifestations, diagnosis and treatment. Refuat Hapeh Vehashinayim. 21: 258-92.

23. Buchner A. and L.S. Hansen, 1980. Amalgam pigmentation (amalgam tattoo) of the oral mucosa A clinicopathologic study of 26 case. Oral surg. oral med. oral pathol., 4992.

24. Martin J.M., E. Magore, A. Cremades, E. Botella Estrada, O. Danmartin, A. Sevila, et al. 2005. An Amalgam Tattoo on the oral mucosa related to a dental prosthesis. J. Eur. Acad. Dermatol. venereol., 19: 90-2.

25. Ristic L., Z. Miljkovic, S. Ilic, T. Duric, 2005. Discolaration of gingiva in the presence of fixes dental restoration. Vojnosant pregl., 62: 371-6.

26. Fardal O., A.C. Johannessen, Morkent, 2005. Gingivomucosal and coetaneous reactions to amalgam fillings. J. clin. periodontal., 32: 430-3.

27. Kock P., F.A. Bahmer, 1999. Oral lesions and symptoms related to metals used in dental restorations: a clinical , allergological, and histologic study. J. Am. Acad. Dermatol., 41:422-30.

28. Pang B.K., S. Freeman, 1995. Oral lichenoid lesions caused by allergy to mercury in amalgam fillings. Contact Dermatitis. 33: 423-7.

29. Issa Y., A.J. Duxbury, T.V. Macfarlan and P.A. Brunton, 2005. Oral lichenoid lesions related to dental restorative materials. British Dental Journal. 198: 361-366.

30. Hernandez E.P., T.M. Botero, M.G. Mantellini, N.J. Mcdonald and J.I.S. Nor, 2005. Effect of proroot MTA mixed with chlorhexidine on apoptosis and cell cycle of fibroblasts and macrophages in vitro. Int. Endod. J., 38: 137-43.

31. Schwengberg S., H. Bohlen, N. Kleinsasser, K. Kehe, M. Seiss, U.I. Walther et al., 2005. In vitro embryo toxicity assessment with dental restorative materials. J. Dent., 33: 49-55.

32. Sideridov I.D. and D.S. Achilias, 2005. Elution study of unreacted Bist -GMA, TEGDMA, UDMA, and Bis EMA form Light- cured Dental Resins and resin composites using HPLC. J. Biomed. Mater. Res., 74: 617-626.

33. Kleinsessar N.H., K. Schmid, A.W. Sassen, U.A. Harreus, K.M. Staudenmaier, M. Folwaczny et al., 2006. Cytotoxic and genotoxic effects of resin monomers in human salivary gland tissue and lymphocytes as assessed by the single cell microgel electrophoresis (comet) assay. Biomaterals, 27: 1762-70.

34. Aoyagi H. and M. Katagiri, 2004. Long - term effects of $\mathrm{Ag}$ - containing alloys on mucous tissue present in biopsy samples. Dent. Mater. J., 23: 340-7.

35. Morken T. and N.R. Gjerdet, 2006. Contact allergy in the mouth. Tidsskr Nor laegeforen. 11: 1372-4.

36. Kaya M., M. Oda, J.L. Ferracone, W. Nakamura, H. Oguchi and H. Sano, 2001. The in-vitro cytotoxicity of eleutes from dentin bonding resins and their effect on tyrosine phosphorylation of L929 cell. Dental materials. 17: 333-339.

37. Dahl J.E., M.J. Frangou-polyzois and G.L. Polyzois, 2006. In vitro biocompatibility of denture relining materials. Gerodontology, 23: 17-22. 